\title{
EFEKTIVITAS MODEL EVALUASI PENDIDIKAN KARAKTER PADA RUMPUN PEMBELAJARAN EKONOMI
}

\author{
Endang Mulyani, Ali Muhson, Sukidjo, Yeni Nur Prilanita, \& Nenden Susilowati \\ Universitas Negeri Yogyakarta, Indonesia \\ endang_mulyani@uny.ac.id,alimuhson@uny.ac.id,sukidjo@uny.ac.id, \\ yeniprilanita@uny.ac.id, nendensusilowati87@uny.ac.id
}

\begin{abstract}
Abstrak: Tujuan dari penelitian ini akan melakukan implementasi Model Evaluasi Pendidikan Karakter pada Rumpun Pembelajaran Ekonom. Penelitian menggunakan pendekatan Research \& Development yang dikembangkan Borg and Gall. Subjek penelitian adalah mahasiswa di Fakultas Ekonomi yang sedang mengambil matakuliah rumpun ekonomi dengan jumlah responden sebanyak 186 mahasiswa yang terdiri empat prodi S1 yang ada di Fakultas Ekonomi. Teknik analisis data yang digunakan adalah uji manova. Hasil dari penelitian ini ada dua. Pertama, asesmen karakter mahasiswa dalam pembelajaran ekonomi menyatakan bahwa pada awal semester (pengamatan awal) karakter mahasiswa cenderung rendah tetapi setelah pengimplementasian pendidikan karakter pada pertengahan semester (pengamatan akhir) karakter mahasiswa cenderung sedang ke tinggi. Kedua, Pembelajaran ekonomi yang menerapkan model evaluasi pendidikan karakter dapat dikatakan efektif dalam meningkatkan karakter mahasiswa. Terbukti dengan adanya rata- rata antara pretest dan posttest yang signifikan.
\end{abstract}

Kata kunci: Model, Evaluasi Pendidikan, Karakter

\section{THE EFFECTIVENESS OF THE EVALUATION MODEL OF CHARACTER EDUCATION IN ECONOMIC LEARNING CLASSES}

\begin{abstract}
This research aims to implement the Character Education Evaluation Model in the Economist Learning Cluster. The study used the Research \& Development approach developed by Borg and Gall. The research subjects were students at the Faculty of Economics. They were taking economic classes with 186 students as respondents consisting of four undergraduate study programs in the Faculty of Economics. The data analysis technique used was the Manova test. The results of this study are twofold. First, the assessment of student character in economic learning states that at the beginning of the semester (initial observation), the character of the student tends to be low, but after the implementation of character education in the middle of the semester (final observation) the character of the student tends to be high. Second, economic learning that applies the character education evaluation model can be effective in improving student character. It is proven by the significant mean between pretest and posttest.
\end{abstract}

Keywords: Model, Educational Evaluation, Character

\section{PENDAHULUAN}

Keefektifan pendidikan karakter yang telah diterapkan dari dulu mulai dipertanyakan. Akhirakhir ini masalah tindakan kekerasan yang dilakukan remaja, khususnya pelajar, banyak mengundang perhatian berbagai pihak (Anshori, 2020). Lebih lanjut dijelaskan bahwa Yogyakarta, yang notabennya adalah kota pelajar pun mulai tercoreng dengan aksi Klitih yang dilakukan oleh anak muda berumur belasan tahun dan masih berstatus sebagai siswa kota tersebut. Dengan seperti itu, implementasi pendidikan di Indonesia khususnya di Yogyakarta belum tercapai seperti yang telah direncanakan (Agung, 2018).

Sekolah hanya menjadi salah satu tempat yang dapat membentuk karakter luhur bagi peserta didik. Kontribusi sekolah dalam pembentukan karakter peserta didik hanya sebesar 30\% sebab 
peserta didik di sekolah tersebut hanya selama 7 jam dalam sehari (Firdaus, 2014). Namun sekolah dituntut memainkan peran penting dalam membantu memecahkan berbagai masalah mendasar dalam hal pembentukan pribadi yang berperilaku etis dan memiliki integritas, atau pengembangan nilai-nilai personal dan sosial di kalangan peserta didik. Tantangan terberat dalam pengembangan pendidikan karakter bagi sekolah yang menjalankan sistem pendidikannya berbasis pendidikan umum adalah selalu bergulat dengan isu etika dan keprihatinan atas rendahnya nilai sosial dan moral peserta didik (Howard et al., 2004).

Inti dari pendidikan karakter merupakan nilai-nilai dasar manusia seperti kejujuran, kebaikan, kedermawanan, keberanian, kebebasan, kesetaraan, dan penghormatan. Inti dari pendidikan karakter tersebut digunakan untuk bekal kehidupan peserta didik dikemudian hari. Pendidikan karakter telah dirumuskan sejak dahulu, namun banyak pendidik yang mengalami permasalahan dalam implementasi evaluasi pendidikan karakter tersebut. Given that many related and unrelated programs fall under the broad rubric of character education, it is understandable that educators have problems in implementing them (Lewis et al., 2011). Tujuan dari penelitian ini melakukan implementasi Model Evaluasi Pendidikan Karakter pada Rumpun Pembelajaran Ekonomi yang bertujuan keefektifan model evaluasi yang telah dikembangkan pada tahun pertama dan kedua. Penelitian ini akan diterapkan di tingkat Perguruan Tinggi khususnya pada Fakultas Ekonomi sebab belum ada model evaluasi pendidikan karakter pada jenjang Perguruan Tinggi serta menimbang pentingnya pendidikan karakter secara berkesinambungan.

\section{METODE}

Penelitian ini termasuk penelitian pengambangan dengan mengembangkan model evaluasi menggunakan pendekatan Research \& Development. Penelitian ini direncanakan dalam 3 (tiga) tahun secara berkelanjutan. Pada tahun ini memasuki tahun ketiga dengan tujuan penelitian adalah mengetahui efektivitas model evaluasi pendidikan karakter pada rumpun pembelajaran ekonomi. Penelitian ini menggunakan metode Research and Development (R\&D) yang dikembangkan oleh (Gall, 2007). Prosedur pengembangan diterapkan dengan Sembilan langkah, yaitu 1) kajian teori dan hasil penelitian, 2) prasurvey, 3) desain model evaluasi, 4) validasi, 5) uji coba terbatas, 6) revisi, 7) uji coba produk, 8) penyempurnaan produk, 9) implementasi/diseminasi terbatas. Tahapan artikel ini masuk dalam tahap terakhir yaitu implementasi model evaluasi. Subjek penelitian ini adalah mahasiswa di Fakultas Ekonomi yang sedang mengambil matakuliah rumpun ekonomi. Pengumpulan data primer dalam penelitian ini dilakukan menggunakan angket. Data yang dikumpulkan dalam penelitian ini mengenai nilai-nilai karakter rumpun ekonomi baik berdasarkan persepsi mahasiswa maupun hasil observasi oleh observer. Teknik analisis data dibagi menjadi dua tahapan, yang pertama dilakukan uji prasyarat yang meliputi uji normalitas dan homogenitas. Tahap kedua yaitu uji hipotesis pada penelitian akan menggunakan uji manova sebab akan mengukur pengaruh variable independen yang berskala kategori terhadap beberapa variabel dependen sekaligus yang berskala data kuantitatif. Uji ini da[at digunakan untuk menentukan apakah terdapat perbedaan signifikan secara statistic pada beberapa variabel yang terjadi secara serentak antara dua tingkatan dalam satu variabel

\section{HASIL DAN PEMBAHASAN}

Penelitian ini dilakukan pada 5 (lima) kelas dengan 4 program studi di fakultas ekonomi, yaitu dua program studi non kependidikan terdiri dari program studi Manajemen dan Akuntansi, serta program studi kependidikan yang terdiri dari Pendidikan Ekonomi dan Pendidikan Akuntansi 
dengan responden sebanyak 186 mahasiswa. Lebih lanjut dapat dicermati pada tabel 1 terkait persebaran responden.

\begin{tabular}{clcc}
\multicolumn{3}{l}{ Tabel 1. Persebaran Responden } \\
\hline No. & \multicolumn{1}{c}{ Program Studi } & Jumlah & Persen \\
\hline 1 & Manajemen & 71 & 38,2 \\
2 & Pendidikan Ekonomi & 38 & 20,4 \\
3 & Akuntansi & 37 & 19,9 \\
4 & Pendidikan Akuntansi & 40 & 21,5 \\
& & 186 & 100 \\
\hline
\end{tabular}

Berdasarkan data tersebut, setiap jurusan terdapat responden yang mewakili dan tidak berpusat pada satu program studi saja. Untuk program studi Manajemen memiliki jumlah responden terbanyak. Terdapat 2 (dua) kelas dalam program studi tersebut yang digunakan untuk penelitian dikarena program studi tersebut memiliki jumlah kelas yang jauh lebih banyak daripada program studi lainnya. Pada program studi lainnya, memiliki kelas paralel sebanyak 2-3 kelas. Sedangkan pada program studi manajemen memiliki kelas paralel sebanyak 6 kelas sehingga program studi tersebut diambil 2 kelas untuk mewakili populasi.

Pendidikan karakter dapat diterapkan dalam pembelajaran (Asriani et al., 2017). Untuk mengetahui karakter secara keseluruhan yang meliputi karakter mandiri, kreatif, inovatif, pantang menyerah, berani mengambil resiko, dan efisien, berdasarkan hasil observasi diperoleh gambaran baik di awal maupun akhir pengamatan sebagai berikut:

Tabel 2. Distribusi Nilai Karakter

\begin{tabular}{|c|c|c|c|c|c|c|c|c|}
\hline \multirow{3}{*}{ Kategori } & \multicolumn{4}{|c|}{ Karakter Awal Semester } & \multicolumn{4}{|c|}{ Karakter Pertengahan Semester } \\
\hline & \multicolumn{2}{|c|}{ Non- Kependidikan } & \multicolumn{2}{|c|}{ Kependidikan } & \multicolumn{2}{|c|}{ Non- Kependidikan } & \multicolumn{2}{|c|}{ Kependidikan } \\
\hline & Frek. & Persen & Frek. & Persen & Frek. & Persen & Frek. & Persen \\
\hline Sangat Rendah & 88 & 47,31 & 70 & 37,63 & 12 & 6,45 & 1 & 0,54 \\
\hline Rendah & 20 & 10,75 & 8 & 4,30 & 62 & 33,33 & 4 & 2,15 \\
\hline Sedang & & & & & 27 & 14,52 & 26 & 13,98 \\
\hline Tinggi & & & & & 4 & 2,15 & 39 & 20,97 \\
\hline Sangat Tinggi & & & & & 3 & 1,61 & 8 & 4,30 \\
\hline Total & & $N=18$ & & & & $\mathrm{~N}=18$ & & \\
\hline
\end{tabular}

Pada pengamatan awal baik di bidang keahlian non kependidikan dan kependidikan memiliki kategori karakter sangat rendah. Terbukti sebanyak 47,31\% responden dari non-kependidikan dan sebanyak 37,63\% dari responden dari kependidikan termasuk dalam kategori sangat rendah. Hal tersebut disebabkan mahasiswa belum memiliki bekal dan gambaran mengenai matakuliah yang akan dijalankan sehingga mahasiswa cenderung akan mengikuti apa yang telah didesain oleh pengampu. Berbeda dengan saat matakuliah tersebut telah berjalan, responden cenderung sudah memiliki gambaran tentang matakuliah. Tidak menutup kemungkinan transfer karakter pun telah berjalan sehingga karakter responden cenderung mulai meningkat. Terbukti pada pengamatan akhir, sebanyak 33,33\% dari non-kependidikan memiliki kategori rendah dan sebanyak 20,97\% dari responden dari kependidikan memiliki kategori tinggi. Tentu kategori tersebut lebih baik daripada kategori sebelumnya. 
Secara matematis, pembelajaran ekonomi yang menerapkan model evaluasi pendidikan karakter dikatakan efektif jika nilai z negatif negatif dan signifikansinya kurang dari 0,05 (O'Regan \& Ghobadian, 2002). Untuk melihat kefektifan model evaluasi pendidikan karakter dapat melalui tabel 3:

Tabel 3. Hasil Uji Hipotesis

\begin{tabular}{clcc}
\hline No & \multicolumn{1}{c}{ Karakter } & $\mathbf{z}$ & Keterangan \\
\hline 1 & Mandiri & $-11,487^{*}$ & Efektif \\
2 & Kreatif & $-11,488^{*}$ & Efektif \\
3 & Inovatif & $-11,391^{*}$ & Efektif \\
4 & Pantang Menyerah & $-10,599^{*}$ & Efektif \\
5 & Keberanian Mengambil Risiko & $-10,965^{*}$ & Efektif \\
6 & Efisien & $-11,660^{*}$ & Efektif \\
7 & Karakter & $-11,730^{*}$ & Efektif \\
\hline & * Signifikansi kurang dari 0,001 & &
\end{tabular}

Berdasarkan analisis deskripsi, pengolahan dan intepretasi data statistik menunjukkan bahwa terdapat tujuh temuan terkait efektivitas model evaluasi pendidikan karakter pada rumpun pembelajaran ekonomi. Pertama, adanya perbedaan kemandirian mahasiswa sebelum dan sesudah diterapkannnya evaluasi pendidikan karakter. Hal ini sejalan dengan penelitian (Anshori, 2020) yang menjelaskan bahwa sikap kemandirian peserta didik mempengaruhi kemampuan pemecahan masalah, sehingga jika kemandirian belajar siswa baik, maka prestasinya pun baik. Hal ini diperkuat juga dengan penelitian (Wuryandani et al., 2016) yang menjelaskan bahwa sikap kemandirian peserta didik dalam belajar membentuk menjadi pribadi yang bisa mengambil keputusan sendiri tanpa bergantung dengan orang lain. Temuan kedua, adanya perbedaan sikap kreatif mahasiswa sebelum dan sesudah diterapkannya evaluasi pendidikan karakter. Hal ini sejalan dengan penelitian (Utami \& Fitriyani, 2017) menjelaskan bahwa sikap kreatif akan terbentuk melalui pembelajaran yang melibatkan proses kinerja. Temuan ketiga, adanya perbedaan sikap inovatif mahasiswa sebelum dan sesudah diterapkannya evaluasi pendidikan karakter. Hal ini sejalan dalam penelitian (Purwadhi, 2019) menjelaskan bahwa sikap inovatif mampu menciptkan suasana pembelajaran yang menyenangkan peserta didik.

Temuan keempat, adanya perbedaan sikap pantang menyerah mahasiswa sebelum dan sesudah diterapkannya evaluasi pendidikan karakter. Hal ini sejalan dengan penelitian yang dilakukan (Maskufah, Fadillah, 2015) menjelaskan bahwa sikap pantang menyerah dalam kelas akan tercipta melalui kegiatan pembelajaran yang menuntut kreativitas siswa. Temuan kelima, adanya perbedaan sikap keberanian mahasiswa sebelum dan sesudah diterapkannya evaluasi pendidikan karakter. Hal ini sesuai dengan penelitian (Rusmana et al., 2018) mengemukakan bahwa sikap berani dalam berpengaruh dalam membina hubungan baik dengan orang lain, sehingga dapat menambah pengetahuan yang mungkin belum diketahui yang dapat menunjang prestasi akademik khususnya maupun non akademik. Temuan, keenam adanya perbedaan sikap efisien mahasiswa sebelum dan sesudah diterapkannya evaluasi pendidikan karakter. Hal ini relevan dengan penelitian yang dilakukan oleh (Hartanto, 2018) mengemukakan bahwa sikap efisien dalam suatu pembelajaran digunakan untuk mengukur ketepatan penguasaan materi dengan waktu yang tersedia. Temuan, ketujuh adanya perbedaan karakter mahasiswa sebelum dan sesudah diterapkannya evaluasi pendidikan karakter. Hal ini sesuai dengan penelitian yang dilakukan oleh (Marzuki, 2012) mengemukakan bahwa berbekal nilai-nilai mulia yang diperoleh melalui proses pembelajaran di kelas dan di luar kelas, mahasiswa diharapkan menjadi manusia yang berkarakter sekaligus memiliki ilmu pengetahuan yang siap dikembangkan. Hal ini diperkuat oleh (Mulyani, 2016) pendidikan karakter siswa dalam pembelajaran di kelas sangat 
mempengaruhi hasil belajar yang dicapai siswa. Jika dari diri siswa tidak membiasakan nilai-nilai karakter dalam pembelajaran maka hasil belajar yang dicapai tidak akan memuaskan, begitu sebaliknya.

\section{SIMPULAN}

Berdasarkan analisis deskripsi, pengolahan dan intepretasi data statistik, dapat disimpulkan menjadi dua kesimpulan sebagai berikut: Pertama, hasil asesmen karakter mahasiswa dalam pembelajaran ekonomi menyatakan bahwa pada awal semester (pengamatan awal) karakter mahasiswa cenderung rendah tetapi setelah pengimplementasian pendidikan karakter pada pertengahan semester (pengamatan akhir) karakter mahasiswa cenderung sedang ke tinggi. Kedua, Pembelajaran ekonomi yang menerapkan model evaluasi pendidikan karakter dapat dikatakan efektif dalam meningkatkan karakter mahasiswa. Terbukti dengan adanya rata- rata antara pretest dan posttest yang signifikan.

\section{DAFTAR PUSTAKA}

Agung, L. (2018). Character Education Integration in Social Studies Learning. Historia: Jurnal Pendidik Dan Peneliti Sejarah, 12(2), 392. https://doi.org/10.17509/historia.v12i2.12111

Anshori, R. (2020). Klitih di Yogyakarta Aksi Kejahatan yang Berulang. Tagar.Id.

Asriani, P., Sa'dijah, C., \& Akbar, S. (2017). Bahan Ajar Berbasis Pendidikan Karakter Untuk. Jurnal Pendidikan: Teori, Penelitian, Dan Pengembangan, 2(11), 1456-1468.

Firdaus, A. Y. (2014). Membangun Karakter Peserta Didik Melalui Pendidikan Berkearifan Lokal. Kompas.

Gall, W. R. B. and M. D. (2007). Educational Research An Introduction. Longman Inc.

Hartanto, W. (2018). Inovasi Media Pembelajaran Mobile Learning (M-Learning): Implementasi, Efisiensi, Efektivitas, dan Daya Tarik. Jurnal FKIP UNNEJ, 408.

Howard, R. W., Berkowitz, M. W., \& Schaeffer, E. F. (2004). Politics of Character Education. Educational Policy, 18(1), 188-215. https://doi.org/10.1177/0895904803260031

Lewis, S. V., Robinson, E. H., \& Hays, B. G. (2011). Implementing an Authentic Character Education Curriculum. Childhood Education, 87(4), 227-231. https://doi.org/10.1080/00094056.2011.10523183

Marzuki. (2012). Pengintegrasian Pendidikan Karakter Dalam Pembelajaran di Sekolah. Jurnal Pendidikan Karakter, 33-44.

Maskufah, Fadillah, M. (2015). Peningkatan Perilaku Pantang Menyerah Melalui Permainan Puzzle Pada Anak Usia 5-6 Di Tk. Jurnal Untan, 5, 1-16.

Mulyani, A. (2016). Pengaruh Pendidikan Karakter Terhadap Hasil Belajar Siswa Dalam Mata Pelajaran Sejarah Kelas XI IIS di SMA Negeri I Wonoayu, Sidoarjo. AVATARA, e-Journal Pendidikan Sejarah, 4(2), 320-328.

O'Regan, N., \& Ghobadian, A. (2002). Effective strategic planning in small and medium sized firms. Management Decision, 40(7), 663-671. https://doi.org/10.1108/00251740210438490

Purwadhi. (2019). Pembelajaran Inovatif dalam Pembentukan Karakter Siswa. Mimbar Pendidikan, 4(1), 21-34. https://doi.org/10.17509/mimbardik.v4i1.16968

Rusmana, F. A., Dahlan, S., \& Andriyanto, R. E. (2018). Peningkatan Keberanian Siswa Berbicara Dalam Diskusi Kelas Menggunakan Konseling Kelompok Dengan Teknik Assertive Training The Improvement Of Students ' Courageousness To Speak In Class Discussion Using Group Conscients Using Assertive Training Techniques. Jurnal Bimbingan 
Jurnal Ekonomi \& Pendidikan, 18(1), 2021

Konseling, 1-13.

Utami, R. D., \& Fitriyani, R. W. (2017). Membangun Karakter Kreatif pada Siswa Sekolah Dasar Melalui Kegiatan Pembuatan Kerajinan Recycle. The 6th University Research Colloquium 2017, 193-198.

Wuryandani, W., Fathurrohman, F., \& Ambarwati, U. (2016). Implementasi Pendidikan Karakter Kemandirian Di Muhammadiyah Boarding School. Jurnal Cakrawala Pendidikan, 15(2), 208-216. https://doi.org/10.21831/cp.v15i2.9882 